\title{
Design and methods for a randomized clinical trial comparing three outreach efforts to improve screening mammography adherence
}

\author{
Mary E Costanza ${ }^{1 *}$, Roger Luckmann², Mary Jo White ${ }^{2}$, Milagros C Rosal ${ }^{1}$, Caroline Cranos ${ }^{2}$, George Reed , \\ Robin Clark ${ }^{3}$, Susan Sama ${ }^{4}$ and Robert Yood ${ }^{4}$
}

\begin{abstract}
Background: Despite the demonstrated need to increase screening mammography utilization and strong evidence that mail and telephone outreach to women can increase screening, most managed care organizations have not adopted comprehensive outreach programs. The uncertainty about optimum strategies and cost effectiveness have retarded widespread acceptance. While $70 \%$ of women report getting a mammogram within the prior 2 years, repeat mammography rates are less than 50\%. This 5-year study is conducted though a Central Massachusetts healthcare plan and affiliated clinic. All womenhave adequate health insurance to cover the test.

Methods/Design: This randomized study compares 3 arms: reminder letter alone; reminder letter plus reminder call; reminder letter plus a second reminder and booklet plus a counselor call. All calls provide women with the opportunity to schedule a mammogram in a reasonable time. The invention period will span 4 years and include repeat attempts. The counselor arm is designed to educate, motivate and counsel women in an effort to alleviate PCP burden. All women who have been in the healthcare plan for 24 months and who have a current primary care provider (PCP) and who are aged 51-84 are randomized to 1 of 3 arms. Interventions are limited to women who become $\geq 18$ months from a prior mammogram. Women and their physicians may opt out of the intervention study. Measurement of completed mammograms will use plan billing records and clinic electronic records. The primary outcome is the proportion of women continuously enrolled for $\geq 24$ months who have had $\geq 1$ mammogram in the last 24 months. Secondary outcomes include the number of women who need repeat interventions. The cost effectiveness analysis will measure all costs from the provider perspective.
\end{abstract}

Discussion: So far, 18,509 women aged 51-84 have been enrolled into our tracking database and were randomized into one of three arms. At baseline, 5,223 women were eligible for an intervention. We anticipate that the outcome will provide firm data about the maximal effectiveness as well as the cost effectiveness of the interventions both for increasing the mammography rate and the repeat mammography rate.

Trial registration: http://clinicaltrials.gov/NCT01332032

\section{Background}

Despite the demonstrated need to increase screening mammography utilization and the strong evidence that mail and telephone outreach to women can increase screening in the short term, most managed care organizations have not adopted comprehensive outreach

\footnotetext{
* Correspondence: mary.costanza@umassmed.edu

'Department of Medicine, University of Massachusetts Medical School, 55 Lake Avenue North, Worcester, MA 01655, USA

Full list of author information is available at the end of the article
}

programs for several reasons: 1) the continuing uncertainty about optimum outreach strategy, 2) the absence of practical and replicable models of such systems and 3) the lack of cost effectiveness data to guide decisionmaking. We undertook this study to compare three successful methods of promoting regular screening mammography (mailed reminders, reminder calls, and more intensive counseling calls) and to identify the most effective and most cost effective of these outreach strategies. Our findings should provide much needed and

\section{Biomed Central}


timely guidance for health plans [1] and Accountable Care Organizations (ACOs).

Determining the most effective way to reach women remains an urgent yet unfinished task. Although public health efforts have been promoting mammography for 25 years or more, national screening rates appear to have stalled. While $81 \%$ of American women, 50-74, report having a mammogram in the previous two years [2], only $46 \%$ woman get them regularly every 1-2 years [3]. A suboptimal level of screening is of considerable concern because the reduction in breast cancer mortality seen with screening mammography requires repeat mammography every several years $[4,5]$. Non-adherent women are at increased risk for developing advanced or non-curable breast cancers when compared to adherent women [6].

The three arms of the study are:

1) RL: A mailed reminder to schedule a mammogram. Mailed reminders have been shown to increase screening mammography rates by $25-50 \%$ [7-11] and have become usual care in some managed care organizations.

2) RC: A mailed reminder followed, if no response, by a reminder telephone call with facilitated access to mammography scheduling. Reminder calls have generally been more effective than reminder letters, especially when the former include the opportunity to schedule a mammogram [12,13]. It is important to confirm this finding in a large population of non-adherent women and especially in women long overdue for a mammogram.

3). ETTC: A mailed reminder followed, if no response, by a mailed educational booklet and, if still no response, by an enhanced tailored telephone counseling call (ETTC). Standard tailored telephone counseling (TTC) has been effective in a wide variety of health promotion outreach efforts [14-21] including efforts focused on cancer prevention and screening [22-25], breast cancer prevention [26] and breast cancer screening [27-33]. TTC has been most effective in breast cancer screening studies when it is used with women who have had a prior mammogram or a recent mammogram but less so in women who had never had a mammogram [27]. Overall, TTC interventions show an improvement in mammography completion rates over mailed reminders or mailed educational materials [13,34-37]. While TTC is often confined to tailored barriers [38], reluctant women may need more encouragement. We developed an enhanced TTC (ETTC) by adding techniques from motivational interviewing [39-43], informative print material and the ability to schedule mammogram on the call. We have pilot tested ETTC and it is effective in helping long overdue women schedule and complete screening mammograms $[44,45]$.

\section{Study goals}

The study goals are:

1) To compare the effectiveness of the three outreach interventions in increasing adherence to mammography screening guidelines in a large managed care population.

2) To identify ways to improve the efficiency and sequencing of the interventions by identifying patient factors and intervention mechanisms associated with increased intervention effectiveness through the evaluation of intermediate outcomes and sub-group analyses.

3) To determine the incremental cost-effectiveness of each telephone intervention compared to the reminder letter and of enhanced tailored telephone counseling to a reminder/scheduling call.

\section{Methods/design \\ Study Design \\ Overall design}

Figure 1 shows the overall design of the study. Beginning in July, 2009, all eligible women are automatically enrolled and randomized 1:1:1 to the three study arms. After approval by PCPs and passive consent, women are entered into the reminder study. The interventions (letters and calls) are directed only to women who have not had a mammogram in $\geq 18$ months. The primary outcome is the proportion of all women who have been enrolled for $\geq 24$ months with a mammogram within the previous 24 months. This outcome will be determined at five times, at baseline and at the end of each intervention year. Outcome at the end of the last intervention year will be the single most important result.

\section{Participants}

All women aged 51-84 in the Fallon Community Health Plan (FCHP), for at least 24 months and have a primary care practitioner (PCP) at Fallon Clinic (FC) are eligible and are randomized to one of the three study arms. Exceptions are women with bilateral mastectomies, in hospice, in permanent nursing home care or those mentally incompetent. There are approximately 20,000 such eligible women ages enrolled in the plan at any given time. As women join the health plan or become 51, once in the plan for 24 months, they are enrolled and randomized into the study cohort. Enrollment into the reminder intervention study requires Primary Care Physician (PCP) approval and passive consent of the woman. PCPs are asked to exclude women using the exclusion criteria (See Table 1). Participants are given an opportunity to opt out of the study prior to being intervened, at the time of any intervention and during any phone call. 


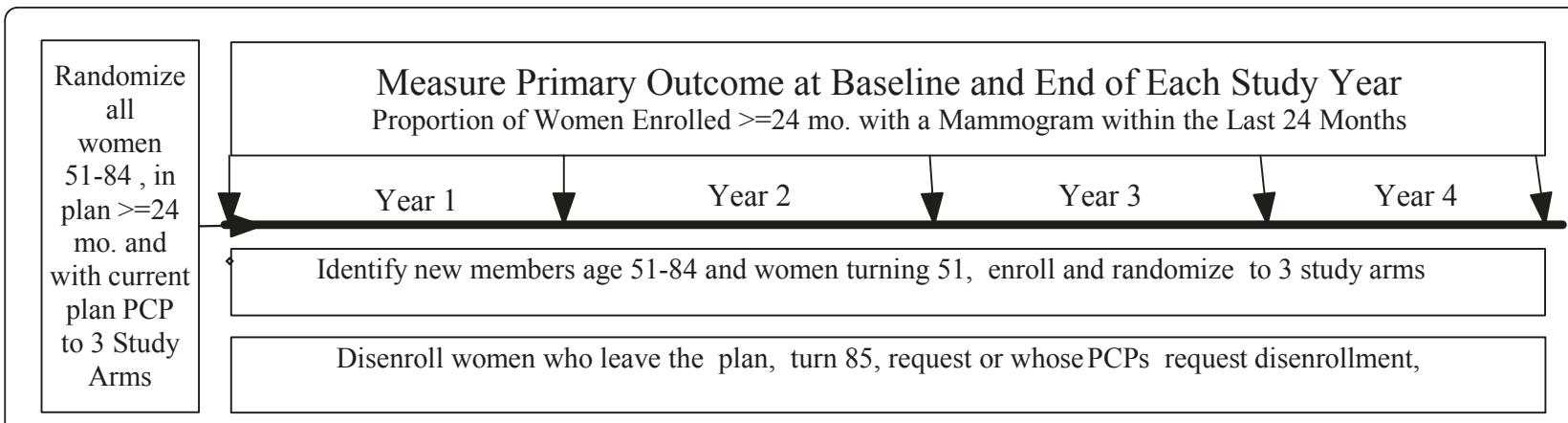

Figure 1 Overview of study design.

\section{Study Setting \\ Study team}

The team includes University of Massachusetts researchers (the study joint principal investigators, project manager, psychologist, health economist, biostatistician) and the Fallon Clinic researchers (the site manager, physician liaison, data analyst, schedulers and counselors). The study was approved by the Institutional Review Board for the Fallon Clinic/Fallon Community Health Plan Research Review Committee (IRB \# 1191). The study will be conducted in compliance with the Helsinki Declaration.

\section{Fallon Community Health Plan (FCHP) and Fallon Clinic Inc. (FC)}

FC is a multi-specialty medical group located in Central Massachusetts with about 250 physicians and 20 medical centers. FC is the main group practice affiliated with FCHP, a mixed-model health maintenance organization (HMO) primarily serving the Central Massachusetts area. Automated tables in the FCHP "Data Warehouse" include in- and outpatient visits, laboratory tests and results, radiology procedures and membership. The FC maintains a centralized data repository with automatic feeds into the electronic record. Because most FC women get their mammograms at FC radiology sites, mammogram scheduled and completed dates are readily accessible. Completion data from non-FC sites are captured in billing and medical records. Although racial characteristics of FCHP members are not systematically captured, they reflect that of the Worcester Metropolitan area, which is about $90 \%$ White and $10 \%$ nonWhite.

\section{Table 1 Eligibility Criteria}

\begin{tabular}{ll}
\hline Inclusion Criteria & Exclusion Criteria \\
\hline \begin{tabular}{ll} 
1. Age 51-84 & 1. History of bilateral mastectomies \\
2. Current patient of Fallon Clinic & 2. Significant cognitive impairment \\
PCP & \\
3. Currently enrolled in FCHP & $\begin{array}{l}\text { 3. Serious illness, precluding } \\
\text { screening }\end{array}$ \\
4. Has a working telephone & 4. Life expectancy $<5$ years \\
\hline
\end{tabular}
\end{tabular}

\section{Health Plan reminder activities include}

An automated reminder call to women a few days before a scheduled mammogram appointment; an annual report to PCPs with the names of women failing to keep their mammogram appointments; at outpatient visits, PCPs receive a reminder in the electronic health record about overdue routine tests, including mammography status. PCPs are neither rewarded nor penalized for their responses.

\section{Provider Responsibilities}

109 of 111 FC PCPs agreed to: 1) participate in the study and 2) allow their patients to join the study, 3) review the list of their potentially eligible patients, 4) eliminate those having an exclusion criterion and 5) approve their electronic signature for personalized reminder letters. Two PCPs declined steps 3-5 and those functions were carried out by the FC study clinician.

\section{Interventions}

Only women $\geq 18$ months from a mammogram receive study interventions. See Figure 2. When women are $\geq$ 18 months from their last mammogram, they all receive the same reminder letter. The letter is electronically signed by a woman's PCP and states: 1) there is no record of a mammogram in the last 18 months, 2) getting regular mammograms every $1-2$ years is important and 3) her PCP recommends that she call the Study Scheduler for a mammogram appointment. When women call, the Study Scheduler uses the same script for all, except as noted below for women in the counseling arm. (See Table 2 for Study Scheduler Protocol)

\section{RL Arm (reminder letter)}

The reminder letter is the only intervention for women in this arm

\section{RC Arm (reminder letter followed by Study Scheduler call)}

All women receive a reminder letter as above. If a woman does not call following receipt of the reminder letter or does not schedule a mammogram on her own within two weeks of the reminder letter, 


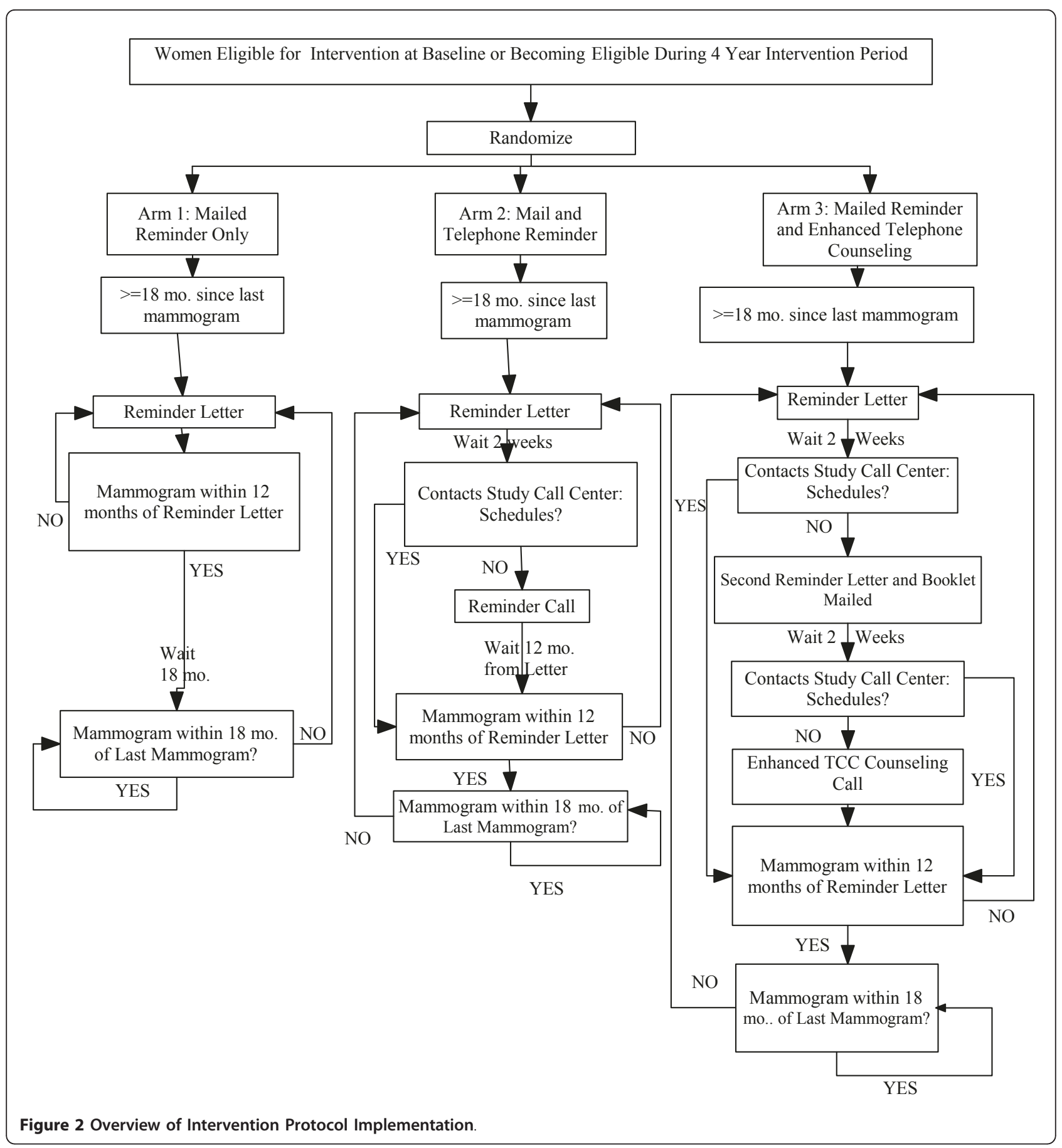

the Study Scheduler makes up to five call-attempts to reach her. The script is the same as noted above.

\section{ETTC Arm: (reminder letters and booklet followed by Counselor call)}

All women receive a reminder letter as above. If a woman calls following receipt of the reminder letter, the Study Scheduler uses the same script as in Table
2 but replaces item \#4 with "Inform the woman that she will receive a mammography booklet but will not get a Counselor call unless she would like to". If a woman calls in to schedule or confirm a mammogram appointment that is inappropriately far in the future, the Scheduler sends a mammography booklet and makes an appointment for her to receive a Counselor call. 
Table 2 Study Scheduler Script for Incoming Calls

\author{
1. Confirm eligibility. \\ 2. Obtain verbal consent for the baseline survey. \\ 3. Stage the subject if the subject is unsure about scheduling, using \\ Tables 3 and 4 . \\ 4. Schedule the mammogram. If the appointment is $<=24$ months \\ from the prior mammogram, reaffirm the importance of keeping on a \\ 12-24 month interval schedule, and remind her to keep the \\ appointment. \\ 5. If a woman wants to schedule or confirm an appointment that is \\ inappropriately far in the future, deliver a brief message reminding the \\ woman that Fallon PCPs recommend mammograms every 12-24 \\ months as the best way to find curable breast cancers. Offer to \\ schedule at a more appropriate interval. \\ 6. Administer the brief baseline survey questions that has 6 socio- \\ demographic questions about ethnicity/race, educational level, working \\ status, smoking, marital and income status.
}

If after receiving the reminder letter, a woman schedules a mammogram on her own, there is no further intervention. If a woman in the counseling arm does not call within two weeks after the first reminder letter, a mammography booklet is sent with a second reminder letter that states that if she does not call or schedule a mammogram within two weeks, a Counselor will call her. If the woman does not respond to the second reminder letter, the Counselor will make five call-attempts.

Counseling calls typically last about 30-35 minutes. If a subject requires a repeat counseling call during the study period, the call content will be different from that of the initial call. During repeat calls, the Counselor will address any change in the subject's stage of readiness, beliefs and barriers. The Counselor protocol using the CATI (computer assisted telephone interviewing) system was detailed in our previous publication $[44,45]$.

\section{Theoretical Basis of the Counseling Intervention:}

1. Our counseling script incorporates a stage-based theory of behavior change that emphasizes the evolution of knowledge and personal risk perception in the development of an intention to act, and the variables that then influence acting on that intention $[46,47]$. The stage-based models have attempted to integrate the conceptual bases and empirical findings of the older models of change to capture the complexities of health behavior. The Precaution Adoption Process Model (PAPM) $[48,49]$ is useful in working with non-adherent women because it classifies them into four stages that provide a more detailed description of the earlier stages of decision-making. In designing the ETTC counseling algorithm, we used our pilot mammography study to adapt the PAPM stages (See Tables 3 \&4) [44,45].

2. The ETTC counseling algorithm interviewing and script use the following (MI) techniques [39]: 1)
Table 3 Staging A Woman's Readiness to Get A

Mammogram

\begin{tabular}{ll}
\hline STAGE & PAPM STAGES REVISED \\
\hline 1 & Unaware - of mammography and guidelines \\
\hline 2 & $\frac{\text { Unengaged - aware but does not see need to get }}{\text { mammogram }}$ \\
\hline 3 & $\frac{\text { Undecided- considering the pros and cons of }}{\text { mammograms }}$ \\
\hline $4 A$ & Definite No - would never get a mammogram \\
\hline $4 B$ & Qualified No - but might reconsider \\
\hline $5 A$ & Definite Yes - planning sometime \\
\hline $5 B$ & Definite Yes - planning soon but cannot set date \\
\hline $5 C$ & Definite Yes - planning soon and can set date \\
\hline
\end{tabular}

expressing empathy through reflective listening skills and a warm empathetic style; 2) developing discrepancy between the patient's current decision and future goals so that the patient verbalizes the need for screening; 3) avoiding argumentation; 4) "rolling with" resistance instead of arguing with it; 5) involving the patient in active problem solving; 6) supporting self-efficacy for screening change by facilitating the patient's own action plan for mammography completion.

\section{Counselor and Study Scheduler Recruitment, Training and Supervision}

The telephone counselors are women with Master's level education or counseling experience. The Counselors train for two weeks in the detailed counseling protocol by a clinical psychologist and an experienced telephone counselor. Training includes: building adequate skills using the CATI system, counseling protocol and materials; role-playing all aspects of the intervention from staging patients to action planning and familiarizing the Counselor with the scheduling procedures. Study Schedulers are Bachelor's prepared Research Assistants with some research experience. The initial training for the

\section{Table 4 Initial Staging Questions}

\footnotetext{
- For those with no record of a mammogram: "Have you ever had a mammogram"?

- If never had a mammogram: "Have you ever heard about a mammogram" "Do you know what a mammogram is?"

- For those who have had a mammogram: "Are you planning or thinking about getting a mammogram?"

- If planning: "Within 3 months?" "More than 3 months?" " Don't know when"

- If planning: "Can I schedule you now? When?"

- If not planning: "Have you decided not to get a mammogram?"

- If decided no: "Have you thought seriously about whether mammograms are for you?"

"Are you unable to decide to get a mammogram?" "Do you mean you would never get

a mammogram or you would not get a mammogram unless something happened?"
} 
Study Scheduler takes 20 hours. Both Counselors and Study Schedulers received didactic presentations on research methods, study goals, breast cancer and mammography screening, systems-based interventions to increase mammography use, screening rates in minority populations and role-playing with study staff and "mock" patients. Selected telephone calls are audio taped and reviewed by the study project manager for quality control and to insure fidelity to protocol. Appropriate refresher/corrective sessions are undertaken as needed.

\section{Repeat interventions (booster doses)}

There are very few studies examining the effect of repeat interventions [13,50-53]. Since the intervention period will span 48 months, we will be able to evaluate the booster effect more fully.

\section{Outcomes}

The primary outcome is the proportion of women continuously enrolled for $\geq 24$ months who have had $\geq 1$ mammogram in the last 24 months. This measure mimics the standard HEDIS (Healthcare Effectiveness and Data Information Set) measure used by most health plans and systems to track mammography utilization, although the HEDIS measure is usually applied only to women age 50-69. The measure is a cross-sectional, prevalence measure that can be applied in a series of static "snapshots" to a dynamically changing population like the one in our study and in any typical health plan.

The secondary outcomes are 1) the number of women in each arm requiring repeat interventions and 2) the immediate outcomes (change in stage of readiness, mammography scheduling for those in the RC and ETTC arms during calls) and short term outcomes (receiving a mammogram within 3 months) following the interventions, for all women receiving the interventions for the first time, adjusted as needed by appropriate covariates (e.g. age, time to last mammogram, marital status and other factors).

The main cost-effectiveness outcome is the incremental cost-effectiveness of each intervention combination, that is, the difference in the percentage of eligible women with mammograms divided by the difference in total cost for each intervention pair. The study also measures separately the startup and operating costs of each intervention.

\section{Data Collection and Management}

During the four-year intervention period the claims database and the electronic health record data base are searched weekly to determine eligibility of women to receive a reminder letter. Study staff enter data on study enrollment when they receive information from PCPs and/or from women relevant to enrollment. The only data required for primary outcome measures on women enrolled in the study are duration of enrollment in FCHP/FC, dates of mammograms, and birth date for developing age-specific outcomes.

Secondary analyses will include subgroup analyses involving the primary outcome, analyses involving secondary outcomes (e.g. change in stage of readiness from beginning to the end of reminder and ETTC calls, completion of scheduled mammograms and time from intervention to mammogram completion) and other analyses requiring independent variables collected from the FCHP database and during all calls from and to subjects. Medicare and Medicaid insurance coverage, history of claims for preventive checkups and other screening tests (e.g. Pap smears, cholesterol, colon cancer screening) will be obtained from FCHP claims databases and the electronic health record database to compare adherence to mammography recommendations to the utilization of other preventive services. (Table 5 shows all of the data sources)

The cost effectiveness analysis will measure all costs from the provider perspective. We will estimate start-up costs and fully staffed operational and cost estimates to give potential adopters a sense of the investment required to implement and maintain each intervention. Start up costs include database and software development and installation, equipment purchases, training costs, and overall administrative costs for the RC and

\section{Table 5 Data Sources for Analysis}

\begin{tabular}{|c|c|c|c|}
\hline Data Sources & $\begin{array}{l}\text { Primary } \\
\text { Outcome } \\
\text { Analysis }\end{array}$ & $\begin{array}{l}\text { Secondary } \\
\text { Data Analyses }\end{array}$ & $\begin{array}{l}\text { Process } \\
\text { Analysis }\end{array}$ \\
\hline $\begin{array}{l}\text { FCHP and FC } \\
\text { Membership Database }\end{array}$ & $x$ & $x$ & $x$ \\
\hline $\begin{array}{l}\text { FCHP Claims Database } \\
\text { and } \\
\text { Electronic Health } \\
\text { Record database }\end{array}$ & $x$ & $x$ & $x$ \\
\hline $\begin{array}{l}\text { Fallon Clinic Scheduling } \\
\text { System }\end{array}$ & & $x$ & $x$ \\
\hline $\begin{array}{l}\text { Patient Survey } \\
\text { (Administered to } \\
\text { subjects } \\
\text { calling the Study } \\
\text { Scheduler or } \\
\text { receiving reminder or } \\
\text { ETTC calls) }\end{array}$ & & $x$ & \\
\hline $\begin{array}{l}\text { ETTC and Reminder } \\
\text { Call CATI System } \\
\text { \& Tracking Database }\end{array}$ & & $x$ & $x$ \\
\hline Phone Call Logs & & & $X$ \\
\hline $\begin{array}{l}\text { PCP Approvals for } \\
\text { Patient Enrollment }\end{array}$ & $x$ & $x$ & $x$ \\
\hline $\begin{array}{l}\text { Patient Refusals of } \\
\text { Enrollment }\end{array}$ & $x$ & $x$ & \\
\hline
\end{tabular}


ETTC interventions. Operational costs include staff and administration salaries, overhead costs (office space, phone, electric, etc.), office supplies, information system and equipment maintenance, and postage. We employ a "micro-costing" approach where units for each component of resource use are measured directly, a unit cost is applied for each and units are multiplied by unit cost to get cost estimates. Staff time and effort involved for all tasks in the intervention are measured using staff logs.

\section{Sample Size and Power \\ Power and Sample Size}

Given, the typical size of the female population ages 5184 at FCHP/FC of 25,000 , we estimated there would be at minimum 15,000 women available for the analyses involving the primary outcome at each year. We explored power to detect differences in primary outcome among intervention groups under two scenarios. Based on findings from our EPICS study [27] we believe that it is reasonable to expect differences of $3-5 \%$ or greater across groups. Differences that are smaller would likely be of little interest to health plans. In the first scenario we assumed that the primary outcome in the RL group remains at $75 \%$, as it is now and that the outcome in the RC group is $80 \%$ and in the ETTC $85 \%$. In the second scenario we assumed these outcomes: RL $80 \%$, RC $83 \%$ and ETTC $86 \%$. With 15,000 in the sample $(5,000$ per group) there is greater than $99 \%$ power to detect the differences proposed or larger ones across groups under both scenarios. For the trends over time there will be approximately $90 \%$ power for an increasing trend over five years leading to a $5 \%$ increase in any group (e.g..75 to.80) based on Cochran-Armitage test of trend with power calculations described by Hintze [54]. Power calculations were carried out using Power Analysis and Sample Size (PASS) 2008.

\section{Proportion needing repeat interventions}

The comparison of rates of repeat interventions will be made between the two call arms of the study (RC and ETTC). We identified sufficient power (greater than $85 \%)$ for differences in proportion needing repeat intervention of $6 \%$ ( $80 \%$ vs. $86 \%$ for example).

\section{Statistical Methods \\ Primary Outcome Analysis: HEDIS-like measure over time}

The unit of randomization and analysis is the individual woman. The primary outcome measure is the proportion of women continuously enrolled for 24 months with $\geq 1$ mammogram in the past 24 months. This will be evaluated at the five measurement time points. The main study finding of interest will be the comparison of this proportion across groups after the last year of intervention (Year 4), because we believe this result best illustrates the magnitude of intervention effect that would be achieved in all future years. The second hypothesis is that the primary outcome measure may change differently over time in the telephone intervention groups because there may be some cumulative effect of repeated interventions on women who do not respond the first time. It is also possible that the interventions may become less effective when applied repeatedly to the same group of women over time. Changes in the composition of the patient population over time could also cause changes in the outcomes. We will estimate the trend over time of the primary outcome within each intervention group and compare the trends over time among the randomized groups. The third hypothesis is that lower age will be associated with a greater response to less intensive interventions. We will investigate this hypothesis through analyses assessing the interaction of subgroups and the intervention arms. To accomplish this and some related analyses involving the primary outcome, we will examine the interactions with intervention group of age, type of medical insurance, and time since last mammogram. Analyses will be carried out using generalized linear models. More specifically, logistic regression models will provide estimates of associations of factors (including the intervention groups) with the primary outcome of mammography screening and adjustment for possible confounders. For models over time with the panel data we will appropriately adjust for correlations using robust variance estimation.

\section{Secondary Outcomes Analyses}

We hypothesize that fewer women who receive the intensive telephone intervention will require a repeat telephone intervention in subsequent years compared to women receiving the brief intervention. For this analysis we will assemble two cohorts of women, one that received ETTC and subsequently received a mammogram within 12 months of the call and another that received a reminder call (RC) and also received a mammogram within 12 months of the call. Proportions scheduling a mammogram within 18 months of the index mammogram and completing a mammogram within 19 months of the index mammogram will be compared between the two intervention arms.

The second hypothesis is that more women who schedule a mammogram after intensive counseling than after a brief reminder call will complete the mammogram. Other secondary analyses will include: 1) analysis of immediate term outcomes (change in stage of readiness, mammography scheduling) and short term outcomes (receiving a mammogram within three months) following telephone interventions, for all women receiving the interventions for the first time, adjusted as needed by appropriate covariates (e.g. age, time to last mammogram, marital status 
and other factors), 2) response to reminder letters measured by the proportion of women without a recent mammogram scheduled or completed who schedule a mammogram within two weeks of a reminder letter, compared to the proportion of women scheduling during other two week intervals, adjusted for age, time to last mammogram, and other factors as appropriate.

\section{Cost and Cost-Effectiveness Analyses (CEA)}

Following similar studies of methods to increase mammography screening, we will conduct the analysis from the perspective of the payer/provider, FCHP/FC $[55,56]$, rather than from the perspective society typically advocated by cost-effectiveness guidelines. Our rationale is that provider costs are the most relevant measure for groups considering adopting the study interventions. Separate comparisons will be conducted for each intervention year including calculating total startup costs for the ETTC and the RC group; calculating the cost of operating each intervention by summing costs for each intervention in each of the four intervention years. Costs for ETTC and RC will be calculated by amortizing startup costs across the fouryear intervention period and adding the operating costs in each year of the intervention. Costs for RL intervention will be based on operating costs only. Recent cancer screening studies have compared differences in total, rather than average, costs across interventions [55-57]. To estimate the incremental costeffectiveness of each intervention combination, we will compare the difference in the percentage of eligible women with mammograms divided by the difference in total cost for each intervention pair. We will report initial results as the incremental cost of increasing ontime mammograms by $1 \%$. This figure can also be converted to an estimated cost per additional mammogram for a hypothetical sample of women. We will conduct sensitivity analyses to determine the effect of including or excluding startup costs, excluding administrative overhead costs, amortizing startup costs over a longer or shorter period, higher or lower (e.g. 10\%) costs for each intervention and higher or lower effectiveness (e.g. $5 \%$ and $10 \%$ variation.)

\section{Randomization}

Patients joining the FCHP are automatically entered into our tracking system if they are female, aged 51-84, have a FC primary care provider and are in the plan for 24 months. Once identified and loaded onto the tracking system, they are automatically randomized to one of the three study arms. No blocking or stratification is used. The tracking database server uses a built-in T-SQL function to randomly allocate a number from 1-3 to each patient. The numbers refer to the specific intervention arm assignment. Documentation of the function can be found at: http:// msdn.microsoft.com/en-us/library/ms177610.aspx

\section{Blinding}

Since women receive different intervention depending on the arm to which they were randomized, blinding of subjects and the staff that receives and makes calls is not possible. Although a woman might reveal what type of contact she had had with study personnel in discussion with her PCP, PCPs are not informed as to which arm a patient is in. While the intervention assignment and the individual mammography outcome is not blinded, overall study arm outcomes will be blinded for all study personnel while the study is ongoing. The statistical team will conduct outcome analyses only at the conclusion of the intervention phase.

\section{Baseline results}

Since July 2009, 18,509 female FCHP/FC enrollees aged 51-84 have been enrolled into our tracking database and were randomized into one of three arms. Table 6 shows their mammogram status at randomization. Table 7 shows the characteristics of the study sample, their approval or non-consent status by age. At baseline, 5,223 women were eligible for an intervention.

\section{Discussion}

The interventions we will evaluate and compare in this study represent system solutions to reminding, scheduling, counseling and motivating women to get regular repeated mammograms. These interventions represent an effort to remove much of the reminder/counseling burden from PCPs and their practice staff. In particular, we are interested in evaluating the effectiveness of a centralized reminder and counseling system as alternative to the primary care providers' (PCPs) role in reminding, educating and/or motivating women to get screening mammography. While many women may be brought to regular on time screening with minimal reminders, women who are significantly overdue for screening or habitually non-compliant need more than

Table 6 Mammogram Status at Study Entry*

\begin{tabular}{lllllll}
\hline Last Mammogram & $<\mathbf{8}$ mo. ago & $\mathbf{1 8 - 2 3}$ mo. ago & $\mathbf{2 4 - 2 9}$ mo. ago & $\mathbf{3 0 - 3 5}$ mo. ago & $\mathbf{2 6 - 4 8}$ mo. ago & $>$ 48 mo. ago \\
\hline$N=18,509$ & 12,808 & 986 & 866 & 599 & 851 & 1,758 \\
$(100.0 \%)$ & $(69.20)$ & $(5.33)$ & $(4.68)$ & $(3.24)$ & $(4.60)$ & $(9.50)$ \\
\hline
\end{tabular}

* Columns do not total to $100 \%$ because of missing data. 
Table 7 Characteristics of Study Sample

\begin{tabular}{|c|c|c|c|c|c|c|}
\hline Age & $\begin{array}{l}\text { Eligible women } \\
\text { at baseline in } \\
\text { study database* }\end{array}$ & $\begin{array}{l}\text { Women opted out of } \\
\text { intervention phase } \\
\text { after broadcast letter }\end{array}$ & $\begin{array}{l}\text { PCP approved } \\
\text { for possible } \\
\text { intervention } \\
\text { phase }\end{array}$ & $\begin{array}{c}\text { Women opted out of } \\
\text { intervention phase at } \\
1^{\text {st }} \text { intervention attempt }\end{array}$ & $\begin{array}{c}\text { Women eligible } \\
\text { for reminder } \\
\text { intervention } \\
\text { study }\end{array}$ & $\begin{array}{l}\text { Women }>=18 \text { months } \\
\text { from last mammogram } \\
\text { and intervention eligible }\end{array}$ \\
\hline $\begin{array}{l}50- \\
59 \\
\end{array}$ & $5,901(31.88)$ & $30(3.44)$ & $5,826(33.62)$ & 12 (20.69) & $5,814(33.66)$ & $1,842(35.27)$ \\
\hline $\begin{array}{l}60- \\
69 \\
\end{array}$ & $4,781(25.83)$ & 115 (13.17) & $4,613(26.62)$ & $13(22.41)$ & $4,600(26.63)$ & $1,146(21.94)$ \\
\hline $\begin{array}{l}70- \\
79 \\
\end{array}$ & $5,429(29.33)$ & $494(56.59)$ & $4,818(27.80)$ & $15(25.86)$ & $4,803(27.81)$ & $1,329(25.45)$ \\
\hline $\begin{array}{l}80- \\
84\end{array}$ & 2,398 (12.96) & $234(26.80)$ & $2,074(11.97)$ & $18(31.03)$ & $2,056(11.90)$ & $906(17.35)$ \\
\hline Total & 18,509 & 873 & 17,331 & 58 & 17,273 & 5,223 \\
\hline
\end{tabular}

*All women 50-84 in FCHP for $\geq 24$ months with current FC PCP and no mammogram in last 4 months.

reminders. We believe counseling and motivating these women will be required. Unfortunately, providers have not been consistently involved in lengthy education or counseling the more reluctant women due to time constraints, limited patient responsiveness, limited PCP training in counseling and limited reimbursement for providing preventive services [58]. Even when providers undertake counseling, it may be brief, incomplete and/ or relatively ineffective due to limited time and training [59-63]. All these problems are compounded by the fact that the numbers of new physicians entering primary care are decreasing significantly and the need for physician extenders is increasing [64]. Finding cost-effective ways to complement PCPs recommendations is critical and the results of this study will be illuminating. In addition, since this study aims to identify the most effective and most cost effective of the outreach strategies, the forthcoming result will provide much needed and timely guidance for health plans [1] and ACOs.

Since the intervention period will span 48 months, we will be able to evaluate the effect of repeated interventions more fully than others have [53]. We hypothesize that woman who respond to an initial intervention may, when coming due for another mammogram, either requires no intervention or a less intense intervention than they responded to initially.

\section{List of Abbreviations}

ACOs: Accountable Care Organizations; CATI: Computer assisted telephone interview; CEA: Cost effectiveness analysis; EPICS: Empowering Physicians to Improve (Breast) Cancer Screening; ETTC: Enhanced tailored telephone counseling call; FC: Fallon Clinic; FCHP: Fallon Community Health Plan; HEDIS: Healthcare Effectiveness and Data Information Set; PAPM: Precaution Adoption Process Model; PASS: Power Analysis and Sample Size; PCP: Primary Care Provider; RC: Reminder call; RL: Reminder letter; TTC: Tailored telephone counseling

\section{Acknowledgements}

The study is funded by the National Institutes of Health, National Cancer Institute (R01CA 132935). The authors acknowledge the contributions of
Amin Vidal for the development of the CATI system and Christine Foley for her work in preparing statistical reports.

\section{Author details}

'Department of Medicine, University of Massachusetts Medical School, 55 Lake Avenue North, Worcester, MA 01655, USA. ²Department of Family Medicine and Community Health, University of Massachusetts Medical School, 55 Lake Avenue North, Worcester, MA 01655, USA. ${ }^{3}$ Center for Health Policy and Research, University of Massachusetts Medical School, 55 Lake Avenue North, Worcester, MA 01655, USA. ${ }^{4}$ Fallon Clinic, 640 Lincoln Street, Worcester, MA 01605, USA.

\section{Authors' contributions}

MEC, RL, MJW, MR, SS, RY participated in the design of the study. MEC, RL, MJW, MR, CC, SS participated in the conceptualization of the interventions. SS, RY contributed to the recruitment of subjects. MEC, RL, MJW, MR, CC, SS, RY participated in implementation of the study. MEC, RL, SS, GR, RC participated in the development of outcome measurement. GR is the biostatistician. All authors reviewed and approved of the final manuscript.

\section{Competing interests}

The authors declare that they have no competing interests.

Received: 29 March 2011 Accepted: 3 June 2011 Published: 3 June 2011

\section{References}

1. American College of Physicians: Information of cost-effectiveness: An essential product of a national effectiveness program. Ann Intern Med 2008, 148(12):956-961.

2. Richardson LC, Rim SH, Plescia M: Vital signs: Breast cancer screening among women aged 50-74 years - United States, 2008. MMWR 2010, 59(26):813-816.

3. Clark MA, Rakowski W, Bonacore LB: Repeat mammography: prevalence estimates and considerations for assessment. Ann Behav Med 2003, 26(3):201-211.

4. Hunt KA, Rosen EL, Sickles EA: Outcome analysis for women undergoing annual versus biennial screening mammography: a review of 24,211 examinations. Am J Roentgenol 1999, 173(2):285-289.

5. Nystrom $L$, Rutquist $L E$, Wall $S$, Lindgren $A$, Linquist $M$, Ryden $S$, et al: Breast cancer screening with mammography: an overview of Swedish randomized trials. Lancet 1993, 341:973-978.

6. Taplin SH, Ichikawa L, Yood MU, Manos MM, Geiger AM, Weinmann S, Gilbert J, Mouchawar J, Leyden WA, Altaras R, Beverly RK, Casso D, Westbrook EO, Bischoff K, Zapka JG, Barlow WE: Reason for late-stage breast cancer: absence of screening or detection, or breakdown in follow-up? J Natl Cancer Inst 2004, 96(20):1518-1527.

7. Taplin SH, Anderman C, Grothaus L, Curry S, Montano D: Using physician correspondence and postcard reminders to promote mammography use. Am J Public Health 1994, 84(4):571-574. 
8. King ES, Rimer BK, Seay J, Balshem A, Engstrom PF: Promoting mammography use through progressive interventions: is it effective? Am J Public Health 1994, 84(1):104-106.

9. Partin MR, Slater JS, Caplan L: Randomized controlled trial of a repeat mammography intervention: Effect of adherence definitions on results. Prev Med 2005, 41(3-4):734-740

10. Quinley J, Mahotière T, Messina CR, Lee TK, Mikail C: Mammographyfacility-based patient reminders and repeat mammograms for Medicare in New York State. Prev Med 2004, 38(1):20-27.

11. Wagner $\mathrm{TH}$ : The effectiveness of mailed patient reminders on mammography screening: a meta-analysis. Am J Prev Med 1998, 14(1):64-70.

12. Davis NA, Nash E, Bailey C, Lewis MJ, Rimer BK, Koplan JP: Evaluation of three methods for improving mammography rates in a managed care plan. Am J Prev Med 1997, 13(4):298-302.

13. Taplin SB, Ludman E, MacLehos R, Meyer D, Seger D, Herta D, Chin C Curry S: Testing reminder and motivational telephone calls to increase screening mammography: a randomized study. J Natl Cancer Inst 2000, 92(3):233-242

14. Lester D: Can we prevent suicide? In AMS Studies in Modern Society. Volume 20. Edited by: Anonymous. New York, NY: AMS Press, Inc; 1989(20)

15. Frank AP, Wandell MG, Headings MD, Conant MA, Woody GE, Michel C Anonymous HIV testing using home collection and telemedicine counseling. Arch Intern Med 1997, 157(3):309-314.

16. Lynch DJ, Tamburrino MB, Nagel R: Telephone counseling for patients with minor depression: preliminary findings in a family practice setting. J Fam Pract 1997, 44(3):293-298.

17. Lane $A B$ : Combining telephone peer counseling and professional services for clients in intensive psychiatric rehabilitation. Psychiatr Serv 1998, 49(3):312-314

18. Leed-Kelly A, Russel KS, Bobo JK, Mcllvain H: Feasibility of smoking cessation counseling by phone with alcohol treatment center graduates. J Subst Abuse Treat 1996, 13(3):203-210.

19. Laken MP, Ager JW: Effects of case management on retention in prenatal substance abuse treatment. Am J Drug Alcohol Abuse 1996, 22(3):439-448

20. Harrison $\mathrm{H}$ : Female abusers: What children and young people have told ChildLine. In Female Sexual Abuse of Children, M. Elliott (ed), Essex" Longman, 95-98. Edited by: Elliott M. New York, NY: Guilford Press; 1994:244.

21. Austin JS, Maisiak RS, Macrina DM, Heck LW: Health outcome improvements in patients with systemic lupus erythematosus using two telephone counseling interventions. Arthritis Care Res 1996, 9(5):391-399.

22. Britt J, Curry SJ, McBride C, Grothaus L, Louie D: Implementation and acceptance of outreach telephone counseling for smoking cessation with nonvolunteer smokers. Health Educ Q 1994, 21:55-68

23. Zhu S, Stretch V, Balabanis M, Rosbrook B, Sadler G, Pierce J: Telephone counseling for smoking cessation: Effects of single-session and multiplesession interventions. J Consult Clin Psychol 1996, 64:202-211.

24. Lerman C, Hanjani P, Caputo C, Miller S, Delmoor E, Nolte S, Engstrom P. Telephone counseling improves adherence to colposcopy among lower income women. J Clin Oncol 1992, 10:330-333.

25. Miller SM, Siejak KK, Schroeder CM, Lerman C, Hernandez E, Helm CW: Enhancing adherence following abnormal Pap smears among lower income minority women: A preventive telephone counseling strategy. $J$ Natl Cancer Inst 1997, 89:703-708.

26. Pierce JP, Faerber S, Wright FA, Newman V, Flatt SW, Kealey SW, Rock CL, Hryniuk W, Greenberg ER: Feasibility of a randomized trial of a highvegetable diet to prevent breast cancer recurrence. Nutr Cancer 1997 28(3):282-288

27. Costanza ME, Stoddard AM, Luckmann R, White MJ, Avrunin JS, Clemow L: Promoting mammography: Results of a randomized trial of telephone counseling and a medical practice intervention. Am J Prev Med 2000, 19(1):39-46

28. Lane DS, Messina CR, Grimson R: An educational approach to improving physician breast cancer screening practices and counseling skills. Patient Educ Couns 2001, 43:287-299.

29. Lipkus IM, Rimer BK, Halabi S, Strigo TS: Can tailored interventions increase mammography use among HMO women? Am J Prev Med 2000, 18(1):1-10.

30. Davis NA, Lewis MJ, Rimer BK, Harvey CM, Koplan JP: Evaluation of a phone intervention to promote mammography in a managed care plan. AJHP 1997, 11:247-249.
31. McBride $C M$, Rimer BK: Using the telephone to improve health behavior and health services delivery. Patient Educ Couns 1999, 37:3-18.

32. Janz NK, Schottenfield D, Doerr KM, Selig SM, Dunn RL, Strawderman M, Levine PA: A two-step intervention to promote mammography screening among women 65 and older. Am J Public Health 1997 87:1683-1686

33. Stockdale SE, Keeler E, Duan N, Derose KP, Fox SA: Costs and costeffectiveness of a church-based intervention to promote mammography screening. Health Serv Res 2000, 35:1037-1057.

34. Rimer BK, Halabi S, Skinner CS, Lipkus I, Strigo TS, Kaplan EB, Samsa GP: Effects of a mammography decision-making intervention at 12 and 24 months. Am J Prev Med 2002, 22:247-257.

35. Rimer B, Halabi S, Skinner CS, Kaplan EB, Crawford Y, Samsa GP, Strigo TS, Lipkus I: The short-term impact of tailored mammography decisionmaking interventions. Patient Educ Couns 2001, 43:269-285

36. Luckmann R, Savageau J, Clemow L, Stoddard A, Costanza M: A randomized trial of telephone counseling to promote screening mammography in two HMOs. Cancer Detect Prev 2003, 27:442-450.

37. Sohl SJ, Moyer A: Tailored interventions to promote mammography screening: A meta-analytic review. Prev Med 2007, 45(4):252-261.

38. Gierisch JM, DeFrank JT, Bowling JM, Rimer BK, Matuszewski JM, Farrell D, Skinner CS: Finding the minimal intervention needed for sustained mammography adherence. Am J Prev Med 2010, 39(4):334-344.

39. Miller W: Motivational interviewing with problem drinkers. Behav Psychother 1983, 11:47-72.

40. Miller W, Rollnick S: Motivational Interviewing: Preparing people to change addictive behaviors New York, NY: Guilford Press; 1991.

41. Rosal MC, Ebbeling CB, Ockene JK, Ockene IS, Herbert JR: Facilitating dietary change: the patient-centered counseling model. J Am Diet Assoc 2001, 101(3):332-341.

42. Emmons KM, Hammond K, Fava JL, Velicer WF, Evans JL, Monroe AD: A randomized trial to reduce passive smoke exposure in low-income households with young children. Pediatrics 2001, 108(1):18-24

43. Resnicow K, Jackson A, Wang T, De AK, McCarty F, Dudley WN, Baranowski T: A motivational interviewing intervention to increase fruit and vegetable intake through Black churches: Results of the Eat for Life trial. Am J Public Health 2001, 91(10):1686-1693.

44. Costanza ME, Luckmann R, White MJ, Rosal MC, LaPelle N, Cranos C: Moving mammogram-reluctant women to screening: A pilot study. Ann Behav Med 2009, 37(3):343-349.

45. LaPelle N, Costanza ME, Luckmann R, Rosal MC, White MJ, Stark JR: Staging mammography nonadherent women: A qualitative study. J Cancer EduC 2008, 23(2):114-121.

46. Prochaska JO, Velicer WF, Rossi JG, Goldstein MG, Marcus BH, Rakowski W, Fiore C, Harlow LL, Redding CA, Rosenbloom D, Rossi SR: Stages of change and decisional balance for 12 problem behaviors. Health Psychol 1994, 13(1):39-46.

47. Rakowski W, Fulton JP, Feldman JP: Women's decision making about mammography: A replication of the relationship between stages of adoption and decisional balance. Health Psychol 1993, 12:209-214.

48. Weinstein ND, Sandman PM: A model of the precaution adoption process: Evidence from home radon testing. Health Psychol 1992 11:170-180.

49. Weinstein ND. The Precaution Adoption Process. Health Psychol 1988 7:355-386

50. Bodiya A, Vorias D, Dickson HA: Does telephone contact with a physician's office staff improve mammogram screening rates? Fam Med 1999, 31(5):324-326.

51. Mayer JA, Lewis EC, Slymen DJ, Dullum J, Kurata H, Holbrook A, Elder JP, Williams SJ: Patient reminder letters to promote annual mammograms: a randomized controlled trial. Prev Med 2000, 31(4):315-322.

52. DeFrank JT, Rimer BK, Gierisch JM, Bowling JM, Farrell D, Skinner CS: Impact of mailed and automated telephone reminders on receipt of repeat mammograms: A randomized controlled trial. Am J Prev Med 2009, 36(6):459-467.

53. Vernon SW, McQueen A, Tiro JA, del Junco DJ: Interventions to promote repeat breast cancer screening with mammography: A systematic review and meta-analysis. J Natl Cancer Inst 2010, 102(14):1023-1039.

54. Hintz J: NCSS and PASS Number cruncher statistical systems Kaysville, Utah; 2004 [http://www.ncss.com]. 
55. Lynch FL, Whitlock EL, Valanis BG, Smith SK: Cost-effectiveness of a tailored intervention to increase screening in $\mathrm{HMO}$ women overdue for Pap test and mammography services. Prev Med 2004, 38:403-411.

56. Saywell RM, Champion VL, Skinner CS, McQuillen D, Martin D, Maraj M: Cost-Effectiveness Comparison of Five Interventions to Increase Mammography Screening. Prev Med 1999, 29:374-382.

57. Wolf MS, Fitzner KA, Powell EF, McCaffrey KR, Pickard AS, McKoy JM, Lindenberg J, Schumock GT, Carson KR, Ferreira MR, Dolan NC, Bennett CL: Costs and cost effectiveness of a health care provider-directed intervention to promote colorectal cancer screening among Veterans. J Clin Oncol 2005, 23(34):8877-8883.

58. Yarnall KSH, Pollak KI, Ostbye T, Krause KM, Michener JL: Primary Care: Is there enough time for prevention? Am J Public Health 2003, 93(4):635-641.

59. Burack RC: Barriers to clinical preventive medicine. Prim Care 1989, 16:245-250.

60. McPhee SJ, Richard RJ, Solkowitz SN: Performance of cancer screening in a university general internal medicine practice: comparison with the 1980 American Cancer Society Guidelines. J Gen Intern Med 1986, 1:275-281

61. Spitz MR, Chamerlain RM, Sider JG, Fueger JJ: Cancer prevention practices among Texas primary care physicians. J Cancer Educ 1992, 7:55-60.

62. Wender RC: Cancer screening and prevention in primary care. Obstacles for physicians. Cancer 1993, 72(3 suppl):1093-1099.

63. Kottke TE, Brekke ML, Solberg LI: Making "time" for preventive services. May Clin Proc 1993, 68:785-791.

64. Cross MA: What the Primary Care Physician Shortage Means for Health Plans. Managed Care Magazine 2007 [http://www.managedcaremag.com/ archives/0706/0706.shortage.html].

\section{Pre-publication history}

The pre-publication history for this paper can be accessed here:

http://www.biomedcentral.com/1472-6963/11/145/prepub

doi:10.1186/1472-6963-11-145

Cite this article as: Costanza et al: Design and methods for a

randomized clinical trial comparing three outreach efforts to improve screening mammography adherence. BMC Health Services Research 2011 11:145.

\section{Submit your next manuscript to BioMed Central and take full advantage of:}

- Convenient online submission

- Thorough peer review

- No space constraints or color figure charges

- Immediate publication on acceptance

- Inclusion in PubMed, CAS, Scopus and Google Scholar

- Research which is freely available for redistribution

Submit your manuscript at www.biomedcentral.com/submit 